\title{
Suppression of Ground Borne Vibration Induced by High-Speed Lines
}

\author{
Ali Mohamed Rathiu, Mohammad Hosseini Fouladi*, Satesh Narayana Namasivayam, \\ Hasina Mamtaz
}

School of Engineering, Taylor's University, Subang Jaya, Selangor, Malaysia

\begin{abstract}
Vibration of high-speed lines leads to annoyance of public and lowering real estate values near the railway lines. This hinders the development of railway infrastructures in urbanised areas. This paper investigates the vibration response of an isolated rail embankment system and modifies the component to better attenuate ground vibration. Mainly velocity response is used to compare the responses and the applied force is of $20 \mathrm{kN}$ at excitation frequencies of $5.6 \mathrm{~Hz}$ and $8.3 \mathrm{~Hz}$. Focus was made on ground-borne vibration and between the frequency range of 0 and 250 Hz. 3D Numerical model was made using SolidWork software and frequency response was produced using Harmonic Analysis module from ANSYS Workbench software. For analytical modelling MATLAB was used along with Simulink to verify the mathematical model. This paper also compares the vibration velocity decibels $(\mathrm{VdB})$ of analytical twodegree of freedom model mathematical model with literature data. Harmonic excitation is used on the track to simulate the moving load of train. The results showed that modified analytical model gives the velocity response of $75 \mathrm{VdB}$ at the maximum peak. Changes brought to the mass and spacing of the sleeper and to the thickness and the corresponding stiffness for the ballast does not result in significant vibration response. Limitations of two-degree analytical model is suspected to be the cause of this inactivity. But resonance vibration can be reduced with the aid of damping coefficient of rail pad. Statistical analysis methods t-test and ANOVA single factor test was used verify the values with $95 \%$ confidence.

Keywords: Vibration, Rail, Embankments, Analytical model, Numerical model.
\end{abstract}

\section{Introduction}

Rail transportation was a novel mode of transportation created during the enlightened era of industrial revolution in $18^{\text {th }}$ century [1]. Back then, the trains were driven by coal powered steam engines which were loud, dirty and puffed out nauseating thick black smoke. Nevertheless, this mode of transportation was popular among people because, compared to

\footnotetext{
* Corresponding author: mfoolady@gmail.com
} 
available alternative modes of transportation, trains had many appealing benefits. These include regular intervals of travelling to a predetermined location safely and cheaply. The benefits have increased over the years with technological advancement in engines which has allowed it to travel much faster and efficiently with cleaner and more powerful diesel engines

This popularity has been retained, despite remarkable advances in automobile technology in recent years. Moreover, train usage is raising in urbanised areas across the world for both developed and developing countries. Abe et al. [2] investigated rail travel demand in Tokyo from 1950 to 2010 and found that the usage was still increasing, with more travellers using underground trains nowadays. Also, a study made on the market competition of the European rail freight trains, which are large cargo trains, by Laroche et al. [3] similarly found that the market was growing despite high initial start-up cost in European Union countries. Furthermore, Chen et al. [4] stated that since the beginning of 2000, Chinese government has started to build a massive rail system infrastructure and the effects of this decision has been beneficial to the economy and livelihood.

Therefore, rail travel is still a booming and essential industry for developed countries and even greater for developing countries. But despite the advances in technology, the current railways still have many issues. The most recognisable problems with the railway are vibration and noise. This paper will focus on the ground-borne vibrations which are caused by the movement of the wheel on the track, which propagates vibration from the track to the surrounding areas. These vibrations can be an annoyance to humans who live in nearby buildings. This becomes more problematic in urbanised cities, as Connolly et al. [5] states that, the economical repercussion due to high vibrations in city areas are more serious as these vibrations can reduce real estate values and can entirely disrupt the work in sensitive workplaces such as record studios, tv studios and theatres. The paper states that even though these sensitive buildings are fewer compared to residential buildings, the high number of reported complaints from these places shows that there is a direct detriment to the working condition of these places due to railway lines. It also cites that ground vibration is also a growing concern in most European countries due to increasing railway lines and soaring frequency of trips per day.

This research investigates and proposes a modified track embankment to suppress the vibrations. To achieve that the components of the embankment needs to be investigated and the influence of the parameters on the vibration needs to be identified through literature review. Referring to the parameters influence on vibration, the components will be modified to form a mathematical model. Analytical calculations using this model will be conducted using MATLAB and numerical calculations using Finite Element analysis will be made using ANSYS software. The analytical and numerical calculations are compared with each other and also verified using literature data.

\subsection{Objectives}

Vibration induced by high speed train is a growing urban issue and mitigating methods needs to be put in place to attenuate the vibrations. Generally, the methods to lower the effects of vibration can be classified into two, which is active mitigation, where modification is applied to the railway support and passive mitigation, where nearby buildings are modified with better vibration damping properties. This paper focuses on active mitigation as this is the most sought out method in real life [4].

To modify the railway support or embankment, the properties of the components which makes up the railway embankment is investigated. Next the properties are altered and the result of that quantified using the research methods of analytical and numerical modelling. 
1. Investigate the parameters which influence ground vibration induced by high speed lines. 2. To modify the embankment components parameters to achieve greater vibration suppression.

3. To verify the accuracy of the analytical and numerical modelling with each other and literature data.

\subsection{Literature review}

\subsubsection{Railway components}

A typical rail embankment has basic four components, track, sleeper, rail pad and ballast, as shown in Figure 1. In addition to these four, external dampers are used in some railways as well. The track is the steel bar on which the train travels and the sleepers are orderly arranged blocks of concrete blocks on which the track is placed. Ballast is the floor which is made from small stones on which the sleeper is placed and half buried in. The rail pad is the placed on the sleeper and acts as the contact to the track. Dampers are external damping structures placed on the track and sleeper to absorb vibrations. The three components to which the parameter changes are made are sleepers, ballast and dampers.

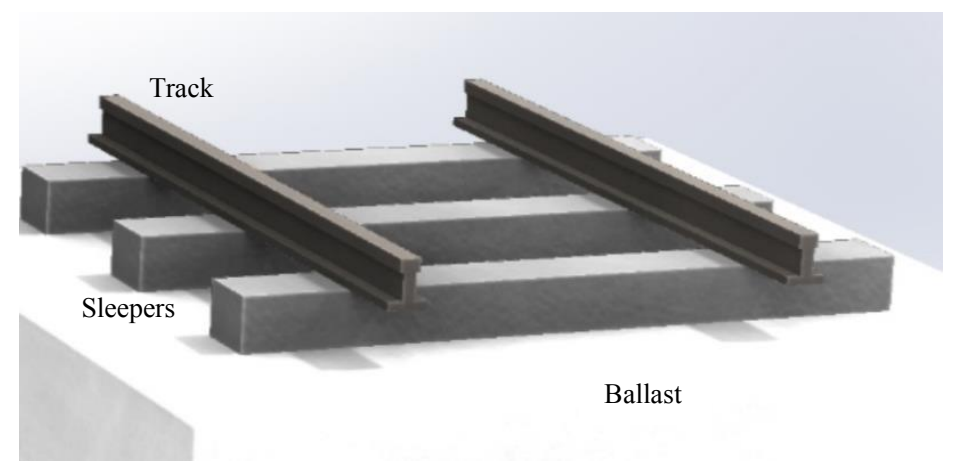

Fig. 1. Rail, sleeper and ballast of a railway embankment.

\subsubsection{Types of Vibration}

Vibration is a periodically repeating motion. When a train moves on a rail embankment, different types of vibrations occurs. Abe et al. [6] states that the main causes for vibration is due to the roughness between the track and the wheel and due to differing stiffness due to periodically placed sleepers. A vibration caused by this sleeper placement is called the pinned-pinned resonance and it occurs when the vibration wavelength is same as the sleeper spacing [7]. Static loading on the track also causes vibration and in Auresh et al [8] it is modelled as a quasi-static load as the load is moved along the track. But it is the wheel/track irregularities which causes most significant vibrations. Nielsen et al. [9], investigates the effect on the track as the wheel becomes more flattened due to skidding and grinding. The results showed that the level of ground vibration was much higher for trains with flattened wheels. 


\subsubsection{Selected parameters}

For sleeper, the parameters selected are spacing between sleepers and its mass. Abe et al. [6] states that by reducing the spacing the pinned-pinned vibration can be reduced. It also a study by Dwight et al. [10] found that mass of the sleeper effects the wave frequencies of the track. The dimension of the sleeper is also investigated because changing the height decreases the bending movement as stated by Kollo et al. [11] and this could influence the vibration as well.

Thickness and stiffness is selected for the ballast as these two parameters can be easily altered by increasing the height by adding more stones and by changing the stiffness by altering the size of the stone. Benedetto et al. [12] investigated the response of a rubber mixed ballast which would have low stiffness and the results should increase in vibration in low frequency bands of $10-30 \mathrm{~Hz}$. Zhang et al. [13] found that the increase in thickness, decreases particle velocity. This would decrease the vibration levels as well.

The influence of rail pad on the vibration and flexural modes of the sleeper was investigated by Kaewunruen et al. [14] with results showing a relation between the rail pad stiffness and the bending mode with generally high stiffness of rail pad, reducing translation and rotational modes. Results also showed that most damage occurs to the sleepers in the resonant frequencies due to the modes of vibration. It is also cited in Abe et al. [6] that the stiffness reduction of the rail pads can influence a lower vibration on the rail system. This component is a focus of this paper due to the ease of adjustability. Changing the rail pad is economically viable compared to changing larger components such as track, sleeper and ballast. Furthermore stiffness and damping are the only variable parameter available for this component since changes to the dimension and mass are limited by the track and sleeper dimensions.

\section{Modelling Methodology}

\subsection{One-dimensional Analytical model and Harmonic excitation}

The literature review showed that the type of model used for study reflected the objectives of that study. For example, Zhang et al. [15] used two-dimensional analytical model as the effect of one unsupported sleeper on the other sleeper is required to be known. For investigation into wheel and track interactions as in the case of Ferrara et al. [16] where a new numerical model to simulate the wheel/track irregularity vibrations is presented and in the case of Nielsen et al. [9] where the vibration and the force impacts caused by damaged wheels are investigates, a non-linear Hertzian theory is used would also mean a twodimensional calculation. As for Dwight et al. [10] which compares the Timoshenko continuous beam theory with semi-analytical finite element (SAFE) calculations uses threedimensional modelling as the lateral in addition to vertical movement of the beam in investigated.

To comply with the objectives of this study, the model uses a one-dimensional model as the effects of direct harmonic load is investigated. Harmonic forces are useful for the investigation as they are continuously applied forces which stimulates the effects of a moving wheel and the consequent stiffness variation in addition to allowing easier understanding of resonances or parametric excitations which provides the maximum values [8]. These extremes are useful to gauge the effectiveness of parameter changes.

Therefore, for this study series of increasing degrees of freedom models up to three degrees of freedom are formed using spring, mass and damping blocks. Only one side of the rail track is used, hence the mass of the ballast and sleeper and excitation force are halved. Further changes to the model are made based on the properties of the components. 


\subsection{Properties of Embankment Components}

The important three components are the mass, damping and stiffness of the components. While mass is an easy property to determine, stiffness and damping are more challenging. Damping of materials is very difficult to discern unless by experimentation [18] and while the stiffness of a component might be simpler in comparison, stiffness changes with the dimension of the component. This is challenging for the ballast where a small volume is required to be isolated to study the effects of vibration. The effort was simplified with the analytical data from Ferrara et al. [16] and Zhai et al. [19]. Table 1 shows the properties of different components. The data is taken from sources which has similarity to parameters which is studied in this research. This includes high-speed trains at least $100 \mathrm{~km} / \mathrm{s}$ of speed, concrete sleeper and at-grade railways (not underground subways or LRTs).

To calculate the stiffness the ground directly below the sleeper is taken in to account in a diverging geometry similar to a trapezoid [19]. This geometry takes in account of the load distribution. Stiffness is calculated by the formula provided by Ferrara et al. [16].

$$
k=\frac{2(l-b) \tan \emptyset}{\ln \left[\frac{l(2 h \times \tan \emptyset+b)}{b(2 h \times \tan \emptyset+l)}\right]} \times E
$$

Table 1. Data for the components.

\begin{tabular}{|l|l|l|l|}
\hline Component & Property & Value & Units \\
\hline Rail track & Mass & 51 & $\mathrm{~kg} / \mathrm{m}$ \\
\hline & Length & 850 & $\mathrm{Mm}$ \\
\hline & Young Modulus & $207[16]$ & $\mathrm{GPa}$ \\
\hline Rail pad & Stiffness & $20-3500[14]$ & $\mathrm{MN} / \mathrm{n}$ \\
\hline & Damping coefficient & $15[9], 20[14] 75[19]$ & $\mathrm{Ns} / \mathrm{m}$ \\
\hline & Size & $148 \times 180 \times 10[20]$ & $\mathrm{Mm}$ \\
\hline Sleeper & Mass (half) & $150[21,19]$ & $\mathrm{Kg}$ \\
\hline & Spacing & $600[6,10]$ & $\mathrm{Mm}$ \\
\hline & Dimension & $1250 \times 250 \times 200[8]$ & $\mathrm{Mm}$ \\
\hline & Poisson Ratio & $0.15[8]$ & \\
\hline & Density & $2500[8], 2750[15]$ & $\mathrm{kg} / \mathrm{m}{ }^{2}$ \\
\hline Ballast & Stiffness & 280.4 & $\mathrm{MN} / \mathrm{m}$ \\
\hline & Damping coefficient & $132[9], 165[15] 58.8[19]$, & $\mathrm{kNs} / \mathrm{m}$ \\
\hline & Modulus of Elasticity & $0.11[19]$ & $\mathrm{GPa}$ \\
\hline & Thickness & $300^{*}(200 \mathrm{~mm}$ subballast $[21]$ & $\mathrm{Mm}$ \\
\hline & Angle & $35[19]$ & $\mathrm{Degree}$ \\
\hline & & & \\
\hline
\end{tabular}




\subsection{Properties of Embankment Components}

The excitation force is the axle load placed on the track from the wheels of the train. This force is not the weight or the static load of the train itself, but the downward force on the track due to the movement of train. In fact, axle load of a train changes with the speed of the train [8]. Similarly, to the embankment properties, the axial force should also match with the experimental excitation. The type of train from which the measurements were taken by Connolly et al. [21] is a high-speed TGV Reseau (TGV), train which operates at an average speed of $294.7 \mathrm{~km} / \mathrm{h}$ or $81.89 \mathrm{~m} / \mathrm{s}$. The axle load on the track only increases up to a certain speed and from then onwards the axial load decreases [8]. Therefore, fast trains such as Sweden's X2000 train which operates at $200 \mathrm{~km} / \mathrm{h} \mathrm{[22]} \mathrm{had} \mathrm{a} \mathrm{lower} \mathrm{axial} \mathrm{load} \mathrm{of}$ $18.25 \mathrm{kN}$ than Spain's Talgo train which operates at $160 \mathrm{~km} / \mathrm{h}$ [23] had a maximum axle load of $75 \mathrm{kN}$. As the axial load of TGV was not provide, an axle load of $20 \mathrm{kN}$ is selected as this value is closer to the axle load of X2000.

The excitation frequency is selected to be $5.6 \mathrm{~Hz}$ and $8.3 \mathrm{~Hz}$ for speed of $200 \mathrm{~km} / \mathrm{h}$ and 300 $\mathrm{km} / \mathrm{h}$ respectively. This is for an axle distance of $10 \mathrm{~m}$.

\subsection{Analytical model using One, Two and Three Degrees of Freedom}

The equation of motion for a single degree mass with damping and stiffness is given by Equation 2 and the harmonic excitation by Equation 3. [24]

$$
\begin{gathered}
m_{T} \ddot{x}+c_{\varepsilon q} \dot{x}+k_{e q} x=0 \\
F \cos (\omega t)
\end{gathered}
$$

Where, $m_{T}$ is the mass. $\bar{x}$ is the acceleration. $c_{e q}$ is the equivalent damping of the system. $\dot{x}$ is the velocity. $k_{e q}$ is the equivalent stiffness of the system and $x$ is the displacement. For the Eq. 2 the force is represented by $F$ and $\omega$ is the driving frequency and $t$ is time.

The amplitude of the steady force response is given by the Equation 4 and the phase, $\varphi$ is given by the Equation 5 .

$$
\begin{gathered}
X=\frac{F}{\sqrt{\left[\left(k_{\mathrm{sq}}-m_{\mathrm{T}} \omega^{2}\right)^{2}+\left(c_{\mathrm{Rq}} \omega\right)^{2}\right]}} \\
\varphi=\tan ^{-1}\left(\frac{2 \pi \omega_{n} \omega}{\omega_{n}^{2}-\omega}\right)
\end{gathered}
$$

Where, $\tau$ is the damping ratio.

The Equations 4 and 5 are used to find the harmonic response of the system. Equation 6 shows the final form of the equation. The homogenous or transient response is not included as the motion begins from zero initial velocity and displacement, therefore these responses will be zero.

$$
x(t)=X \sin (\omega t-\varphi)
$$

The analytical model is also verified using MATLAB Simulink model shown in Figure 2. The results from Equation 6 is verified by the Simulink model which is a second order model calculated using ordinary differential equation of Dormand-Prince method. 


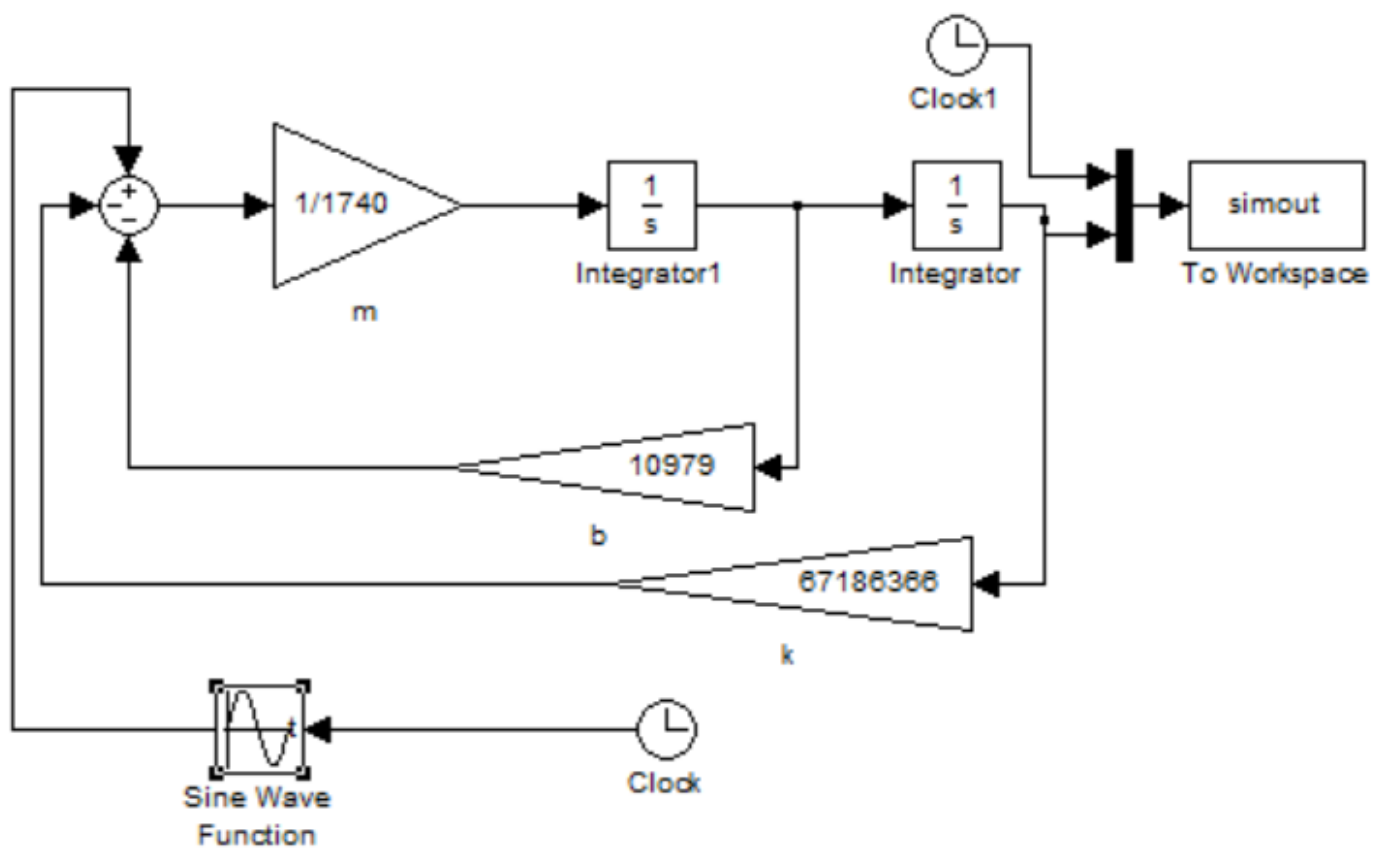

Fig. 2. Simulink model for harmonic excitation for a spring damper system.

Multi-degree of freedom models is more complicated than one degree of freedom as each mass are coupled with the subsequent masses. Therefore, decoupling is required to measure the individual response of the mass. Equations 7 and 8 shows that general twodegree and three-degree of freedom system under harmonic force.

$$
\begin{aligned}
& {\left[\begin{array}{cc}
m_{1} & 0 \\
0 & m_{2}
\end{array}\right]\left\{\begin{array}{l}
\bar{x}_{1} \\
\bar{x}_{2}
\end{array}\right\}+\left[\begin{array}{cc}
c_{1}+c_{2} & -c_{2} \\
-c_{2} & c_{2}
\end{array}\right]\left\{\begin{array}{l}
x_{1} \\
\dot{x}_{2}
\end{array}\right\}+\left[\begin{array}{cc}
k_{1}+k_{2} & -k_{2} \\
-k_{2} & k_{2}
\end{array}\right]\left\{\begin{array}{l}
x_{1} \\
x_{2}
\end{array}\right\}=\left\{\begin{array}{l}
1 \\
0
\end{array}\right\} F e^{i \omega t}} \\
& \left.\left[\begin{array}{ccc}
m_{1} & 0 & 0 \\
0 & m_{2} & 0 \\
0 & 0 & m_{a}
\end{array}\right]\left\{\begin{array}{l}
\bar{x}_{1} \\
\ddot{x}_{2} \\
\bar{x}_{a}
\end{array}\right\}+\left[\begin{array}{ccc}
c_{1}+c_{2} & -c_{2} & 0 \\
-c_{2} & c_{2}+c_{a} & -c_{a} \\
0 & -c_{a} & c_{3}
\end{array}\right] \begin{array}{l}
\dot{x}_{1} \\
\dot{x}_{2} \\
\dot{x}_{3}
\end{array}\right\} \\
& +\left[\begin{array}{ccc}
k_{1}+k_{2} & -k_{2} & 0 \\
-k_{2} & k_{2}+k_{a} & -k_{a} \\
0 & -k_{a} & k_{a}
\end{array}\right]\left\{\begin{array}{l}
x_{1} \\
x_{2} \\
x_{a}
\end{array}\right\}=\left\{\begin{array}{l}
1 \\
0 \\
0
\end{array}\right\} F \cos \omega t
\end{aligned}
$$

Beginning from three-degree of freedom, Equation 8 shows the general system of Figure 3. The masses from top to bottom with the subscript 1,2 and 3 are of track, sleeper and ballast. The stiffness and damping coefficient of subscript 1 are of the rail pad, then for the ballast for subscript 2 and 3. As the force is applied on the track, only the first matrix for force is placed by a harmonic excitation while the rest are zero.

For the two-degree of freedom, in Equation 7 the mass $\left(m_{1}\right)$ combines the mass of track and the sleeper. Also stiffness and the damping are for the rail pad and for ballast. The property of ballast is not duplicated as in the three-degree of freedom equation. 


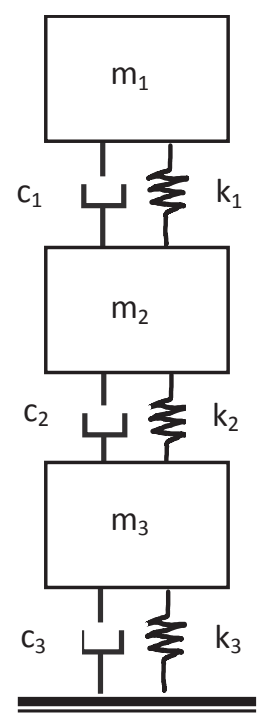

Fig. 3. Three degree of freedom system.

Two separate methods have been used for solving the Equations 7 and 8. For twodegree of freedom system, mechanical impedance $Z(i \omega)$ is used to find the response for the two-degree of freedom displacement, velocity and acceleration as shown in Equations 9 13.

$$
\begin{aligned}
& x_{1}(t)=X_{1} e^{i \omega t} \\
& x_{2}(t)=X_{2} e^{i \omega t}
\end{aligned}
$$

Equations 9 and 10 are steady state displacement solution for the amplitudes $X_{1}$ and $X_{2}$ with the forcing frequency of $\omega$. The values for the amplitudes are obtained from the mechanical impedance Equations 12 and 13.

$$
Z_{r g}(i \omega)=-\omega^{2} m_{r g}+i \omega_{r g}+k_{r g}
$$

The subscript rs corresponds to the location of the property in the matrices in Equation 7.

$$
\begin{aligned}
& X_{1}=\frac{z_{22}(i \omega) F_{10}}{z_{11}(i \omega) z_{22}(i \omega)-z_{12}^{2}(i \omega)} \\
& X_{2}=\frac{-z_{12}(i \omega) F_{10}}{z_{11}(i \omega) z_{22}(i \omega)-z_{12}^{2}(i \omega)}
\end{aligned}
$$

But substituting the values of $X_{1}$ and $X_{2}$ to Equations 9 and 10, the displacement due to force can be calculated. To find the velocity and the acceleration the Equations 9 and 10 are differentiated once for velocity and twice for acceleration.

An easier route has been taken for three-degree of freedom equation by using MATLAB ordinary differential equation 23 for calculation. Appendix A shows the differential equations used where the three equations from the matric in Equation 8 is set as six first order differential equations. 
Another important formula for quantifying the level of vibration is decibels formula Equation 14. Decibels helps to standardise results so that it can be compared with data from other sources [25].

$$
L_{v}=20 \log _{10}\left(\frac{v}{v_{r z f}}\right)
$$

$\mathrm{L}_{\mathrm{v}}$ is the velocity level represented in decibels and $v_{\text {ref }}$ is the reference velocity. This velocity is an accepted value for reference agencies such as International Organisation for Standardisation (ISO) and Federal Transit Administration (FTA). The value used in this paper is $2.54 \times 10^{-8} \mathrm{~m} / \mathrm{s}$ which is the value used by the FTA [25].

\subsection{Numerical modelling}

Similar to the analytical model, the numerical model uses a single track, sleeper and ballast is shown in Figure 4. But in addition to the analytical modelling a rail pad is modelled and placed as well. Furthermore, the ballast was modelled in a trapezoid geometry for model A and model B uses two sleepers to test the response due to varying the sleeper distance. The components where modelled from SOLIDWORK and was imported to ANSYS Workbench. The bodies were given the material properties and then Harmonic Response module was selected to apply a force of $10000 \mathrm{~N}$ on the track surface. The boundary condition is set as frictionless support and the frequency range is selected from 0 to $250 \mathrm{~Hz}$ with $10 \mathrm{~Hz}$ increment. Same properties from Table 1 is used for the material data.

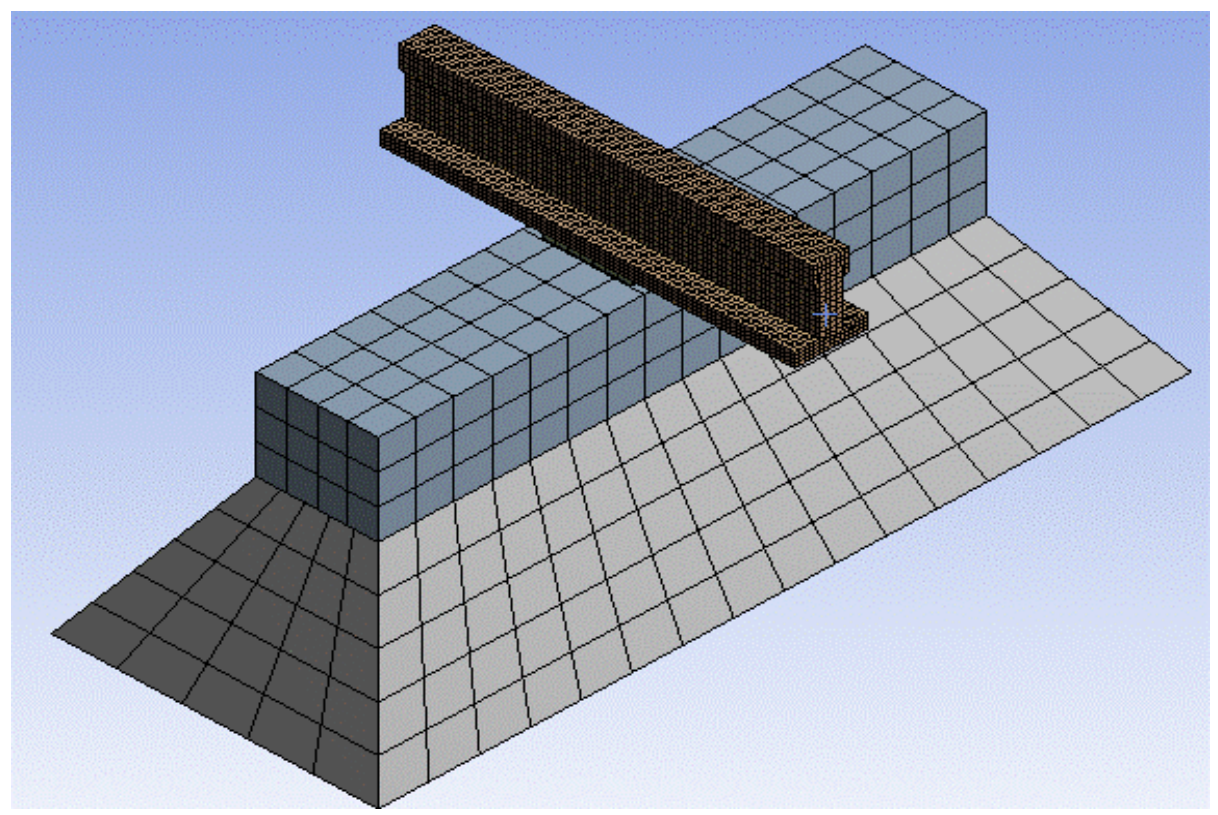

Fig. 4. One sleeper model A. 


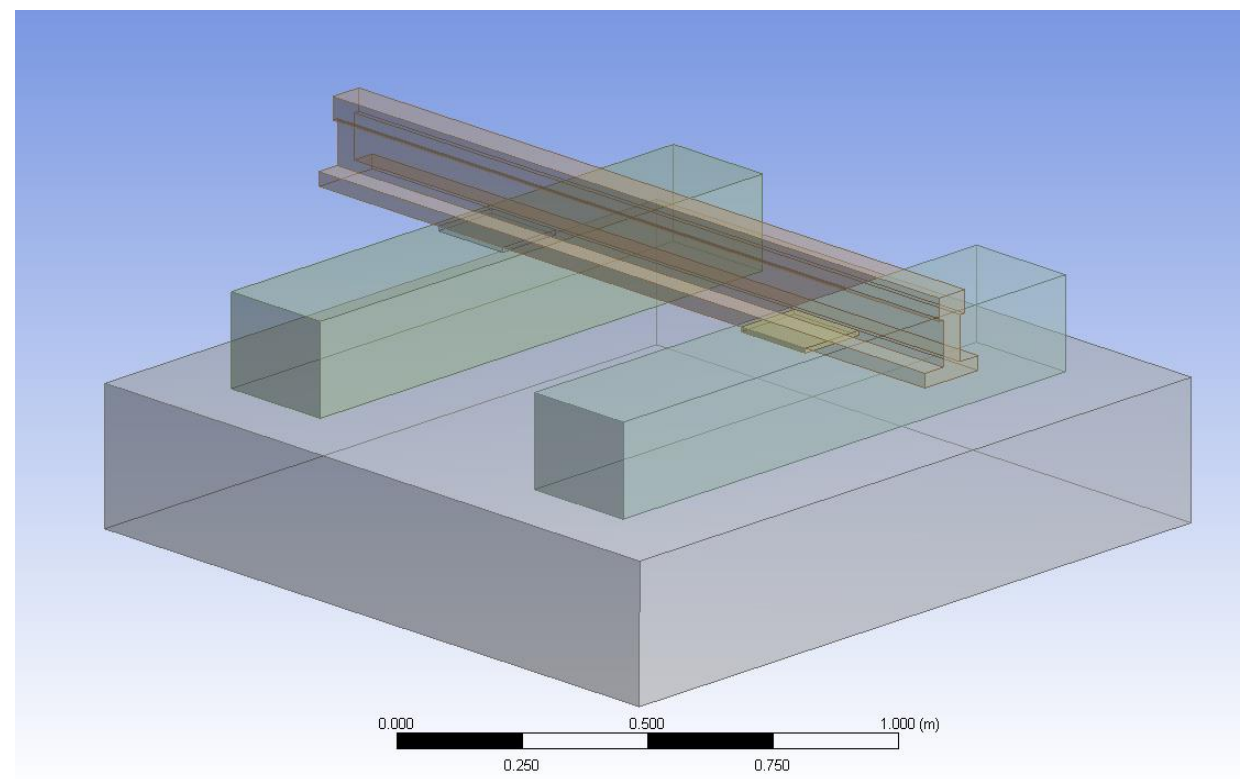

Fig. 5. Numerical model of the track, sleeper and ballast with the force being applied to the track in negative y-direction.

Table 2. Mesh Property of Model A and B

\begin{tabular}{|l|l|l|}
\hline Mesh Property & Model A, one sleeper & Model B, two sleepers \\
\hline Element size & $\begin{array}{l}\text { For track } 0.01 \mathrm{~m} \\
\text { Rest of the body Automatic }\end{array}$ & $\begin{array}{l}\text { For track } 0.01 \mathrm{~m} \\
\text { Rest of the body Automatic }\end{array}$ \\
\hline Meshing Method & Hexagonal & Hexagonal \\
\hline Number of Elements & 61714 & 1339267 \\
\hline Element Quality & 0.955 & 0.962 \\
\hline Skewness & 0.0574 & 0.0486 \\
\hline
\end{tabular}

\section{Results and Discussion of Analytical and Numerical Modelling}

The analytical model is done using formulas and calculations. Therefore, an error might occur in the calculations which might offset the results. To verify that there is no such error, Simulink model is made to calculate the harmonic motion of a second order differential equation. The results showed that there is observable correlation, and this is statistically proven with the Table 3. Pearson correlation, which indicates strong relation between the two means as the value is close to value one, and the value of the statistical test, 0.9733 is very close to one. Furthermore, the t-critical is much higher than the t-statistical value, hence there is $95 \%$ confidence that the mean is similar.

There are many disadvantages of using the one-degree of freedom as the effects of individual components properties cannot be discussed as the total and equivalent values are used. Therefore, the second-degree of freedom model from Equations 9 and 10 are used to provide the results. The results are formed with velocity response for two masses. The first mass is the total mass of track and sleeper and the second mass is that of the ballast. These results are also given in frequency domain as well to compare with the numerical results for harmonic excitation. The three-degree of freedom is not used because second-degree od freedom model is easier to convert to velocity response and the mass of track and sleeper is not large compared to ballast, so they can be combined. 


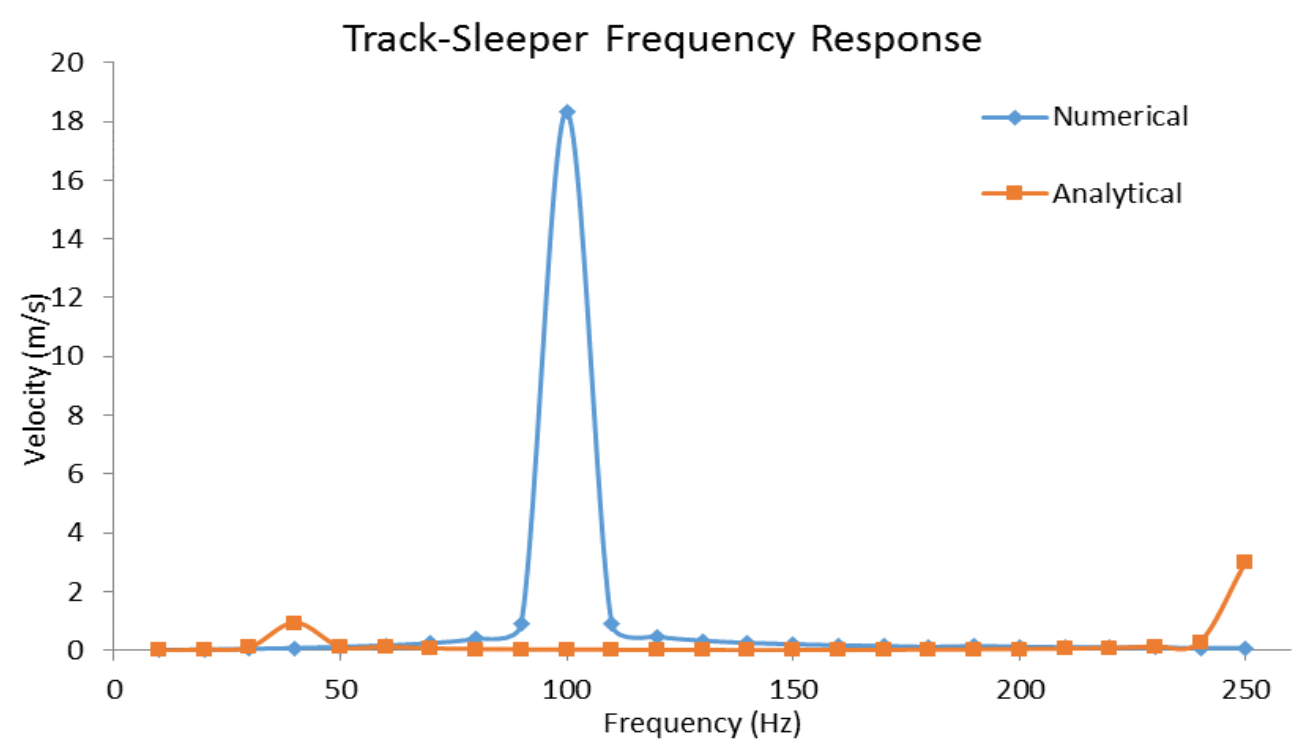

Fig. 6. Velocity frequency of numerical and analytical second-degree freedom model for tracksleeper.

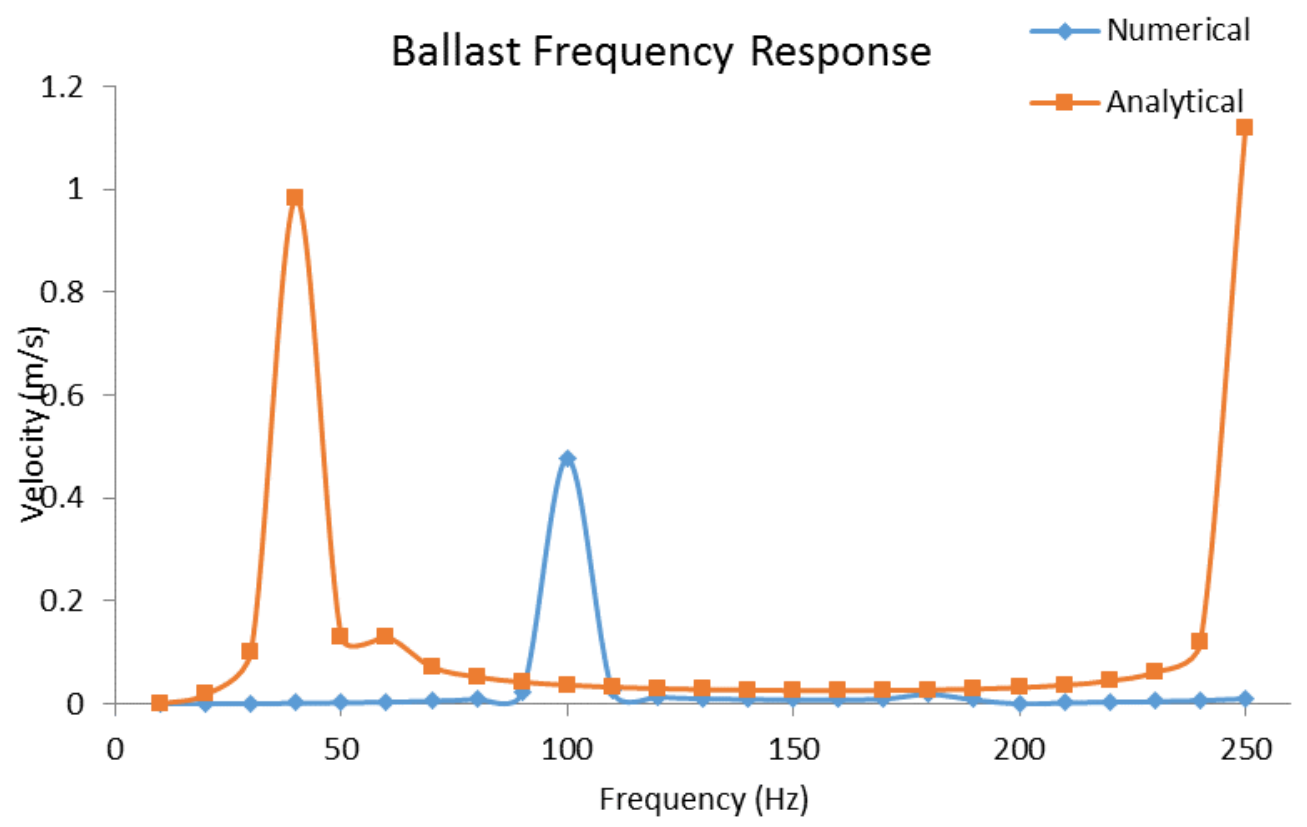

Fig. 7. Velocity frequency of numerical and analytical second-degree freedom model for ballast

While, the visual comparison between the numerical and the analytical model, Figures 6 and 8 might seem apparent because of the peaks, the lower values remain close to each other for both figures. Provides $95 \%$ confidence that the means are the same for both of the 
models. The t-statistical is lower than the t-critical for both the tests but the Pearson Correlation is low. This means that while correlation is not very high, the means are nevertheless same. The peaks for numerical model is at $100 \mathrm{~Hz}$ and for analytical at 40 and $250 \mathrm{~Hz}$. The modal simulation using ANSYS Workbench modal analysis module shows that at $100 \mathrm{~Hz}$ the natural frequency of the rail pad is reached as shown in Figure 8. This causes the high vibration response. Therefore, the excitation frequency must not reach this $100 \mathrm{~Hz}$ while using the rail pad with this particular stiffness form Table 1 of $20 \mathrm{MN} / \mathrm{m}$.

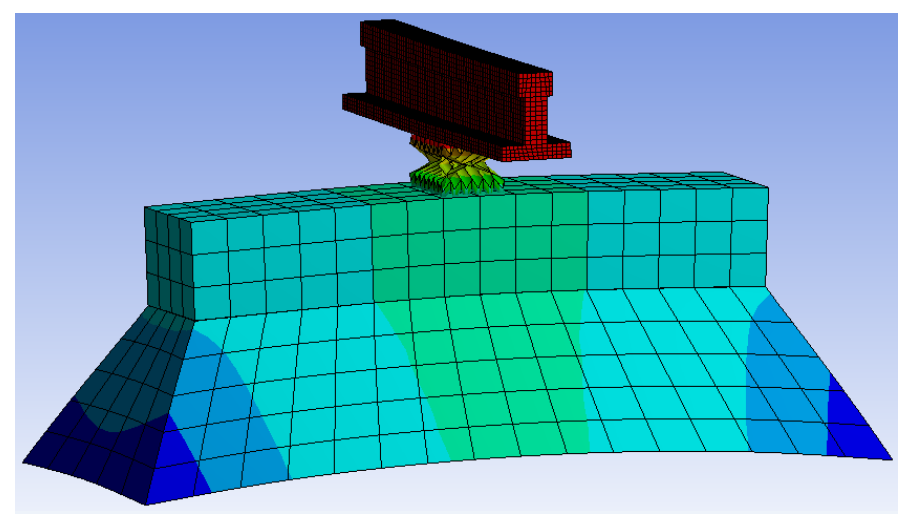

Fig. 8. Modal analysis for numerical Model A using modal analysis

Table 3. Paired Two Sample for Means t-test for Analytical and Simulink results

\begin{tabular}{|l|r|r|}
\hline & Simulink & Analytical \\
\hline Mean & & 7.56E-06 \\
\hline Variance & $1.48 \mathrm{E}-05$ & $1.82 \mathrm{E}-07$ \\
\hline Observations & 21 & 21 \\
\hline & & \\
\hline Pearson Correlation & $\underline{0.973328}$ & \\
\hline Hypothesized Mean & & \\
Difference & $\underline{0.317091}$ & \\
\hline Degree of Freedom & $\underline{0.754461}$ & \\
\hline t Stat & $\underline{0.973328}$ & \\
\hline P(T<=t) two-tail & & \\
\hline t Critical two-tail & & \\
\hline Mean & & \\
\hline
\end{tabular}




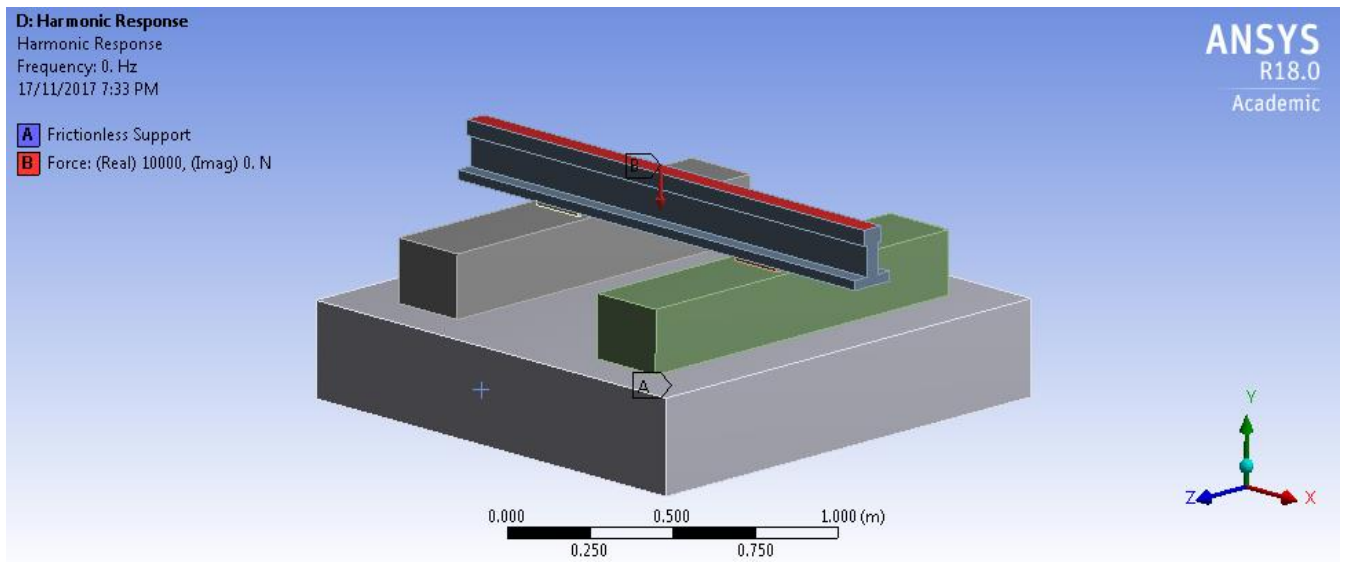

Fig. 9. Model used to study the vibration response to different sleeper spacing

Numerical model to investigate the relation between acceleration response due to sleeper distances of 50,60 and $70 \mathrm{~cm}$ was simulated using the model as shown in Figure 9. The results provided in Appendix B gave insufficient difference to the response. This is validated using ANOVA test in Table 4. where the F-critical 3.12 is greater than F-statistics of 1.88. The reason for using ANOVA is that means of three sets needed to be compared.

Table 4. Show the summary of variance of the sleeper spacing and the F-test

\begin{tabular}{|c|c|c|c|c|c|c|}
\hline \multicolumn{7}{|l|}{ SUMMARY } \\
\hline Groups & Count & Sum & Average & Variance & & \\
\hline $50 \mathrm{~cm}$ & 25 & 14.24983 & 0.569993 & 0.805951 & & \\
\hline $60 \mathrm{~cm}$ & 25 & 208.6954 & 8.347815 & 578.3901 & & \\
\hline $70 \mathrm{~cm}$ & 25 & 77.36599 & 3.09464 & 48.01165 & & \\
\hline \multicolumn{7}{|l|}{ ANOVA } \\
\hline Source of & & & & & & \\
\hline Variation & $S S$ & $d f$ & $M S$ & $F$ & P-value & $F$ crit \\
\hline Between Groups & 787.2018 & 2 & 393.6009 & 1.882634 & 0.159604 & 3.123907 \\
\hline Within Groups & 15052.99 & 72 & 209.0692 & & & \\
\hline Total & 15840.19 & 74 & & & & \\
\hline
\end{tabular}




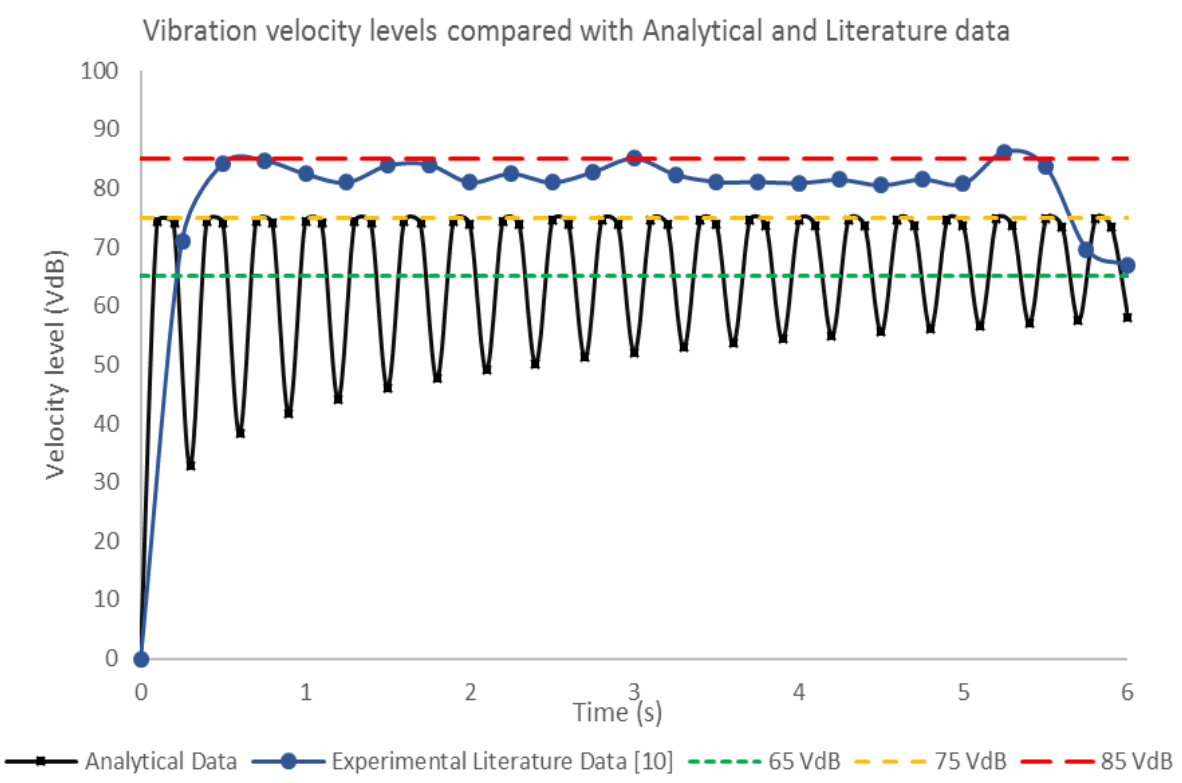

Fig. 10. Actual literature data compared with analytical data with benchmarking of $65 \mathrm{VdB}, 75 \mathrm{VdB}$ and $85 \mathrm{VdB}$

It was found out by analytical calculations that rail pad stiffness produces high response on the vibration of the system. Therefore, using Matlab, the lowest possible value of vibration was produced with the provided pad stiffness from Table 1 . The as the stiffness increases the vibration of the system decreased. Therefore, the highest stiffness value of $3500 \mathrm{MN} / \mathrm{m}$ value was used. This material corresponds to high density Ethylene vinyl acetate polymer (EVA) [14]. The maximum value from the analytical data was compared for the frequency using alternatively 5.6 and $8.3 \mathrm{~Hz}$. As $8.3 \mathrm{~Hz}$ had higher magnitudes it was selected.

The lowest analytical vibration response was then converted to velocity decibels which has the reference value of $2.54 \times 10^{-8} \mathrm{~m} / \mathrm{s}$ [25] to make it easier to compare with the benchmark values. In Figure 10, three dashed lines of values 65, 75 and $85 \mathrm{VdB}$ are the three bands of vibration levels which will be felt by humans with the intensity increasing with the values. This is stated in the "Transit Noise and Vibration Impact Assessment", released by American Federal Transit Administration (FTA) [25], that while $65 \mathrm{VdB}$ is barely precipitable for humans and $75 \mathrm{VdB}$ can be annoying for some, at $85 \mathrm{VdB}$ people will find this level disruptive and is acceptable if only infrequent amount of trips.

Changes to the rail pad stiffness is effective for suppressing vibrations which is shown in Figure 10 . This statistically proven with ANOVA single factor test of $95 \%$ confidence in Table 5 as the F-statistical values of 8.47 larger than 3.95 F-critical. ANOVA single factor was used due to the difference in count for the results. 
Table 5. Show the summary of variance of the analytical and literature data and the F-test

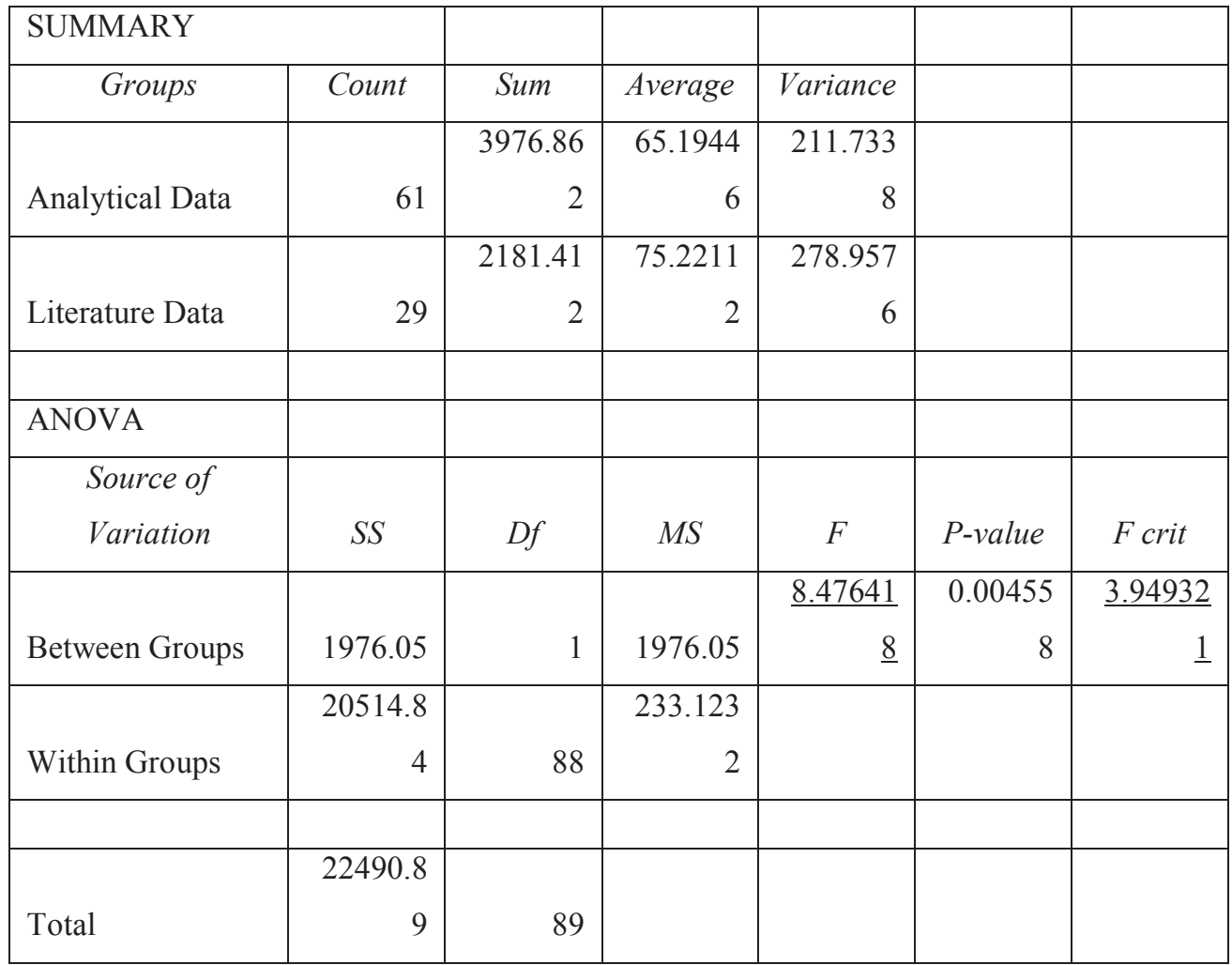

\section{Conclusions}

In this study, a simplified analytical model and a numerical model is made to understand the vibration response due to a train load which is simulated by harmonic excitation. The numerical modelling showed that a resonance does occur $100 \mathrm{~Hz}$ range which belongs to the rail pad. List of components of the rail embankment has been reviewed using journal articles and their vibration influencing parameters in addition to their other properties have been complied and refined to make sure they meet the scope of the project. Then analytical and numerical models where created using ANSYS and Matlab for numerical and analytical respectively. A model very closed to the actual literature data was made and the vibration was supressed by increasing the rail pad stiffness. Comparison between the modified analytical model gives the velocity response of $75 \mathrm{VdB}$ as the maximum peak.

Two-dimensional modelling is required to investigate more complex vibrations and also take in the influence of geometry of the components such as sleeper spacing. Also scope of the project needs to be more focused on particular train or trains from certain region, as different regions uses different types of trains and embankment. Most importantly an acoustic assessment is required to understand the noise generated under the new rail pad stiffness. If the stiffness had worsened the noise, other methods needs to be explored such as using external dampers.

\section{References}


1. H. Williams, Road and rail transportation, 1st ed. New York: Facts on File, 5052(2004).

2. R. Abe and H. Kato, What led to the establishment of a rail-oriented city? Determinants of urban rail supply in Tokyo, Japan, 1950-2010, TRANSPORT POLICY, 58, 72-79 (2017).

3. F. Laroche, C. Sys, T. Vanelslander, E. Van de Voorde, Imperfect competition in a network industry: The case of the European rail freight market, TRANSPORT POLICY, 58, 53-61 (2017).

4. Z. Chen, J. Xue, A. Rose, K. Haynes, The impact of high-speed rail investment on economic and environmental change in China: A dynamic CGE analysis, Transp Res Part A Policy Pract, 92, 232-245 (2016).

5. D. Connolly, G. Marecki, G. Kouroussis, I. Thalassinakis, P. Woodward, The growth of railway ground vibration problems - A review, Sci Total Environ, 568, 1276-1282 (2016).

6. K. Abe, Y. Chida, P. E. Balde Quinay, K. Koro, "Dynamic instability of a wheel moving on a discretely supported infinite rail," J. Sound Vib., 333, no. 15, 3413-3427 (2014).

7. N. Persson, Predicting Railway-Induced Ground Vibrations, Post Graduate, Lung University (2016).

8. L. Auersch, The excitation of ground vibration by rail traffic: Theory of vehicle-tracksoil interaction and measurements on high-speed lines, J. Sound Vib., 284, no. 1-2, 103-132 (2005).

9. J. C. O. Nielsen, G. Lombaert, S. François, A hybrid model for prediction of groundborne vibration due to discrete wheel/rail irregularities, J. Sound Vib., 345, 103-120 (2015).

10. W. Li, R. A. Dwight, T. Zhang, On the study of vibration of a supported railway rail using the semi-analytical finite element method, J. Sound Vib., 345, 121-145 (2015).

11. S. A. Köllö, G. Köllő, A. Puskás, Nexus of the Load Bearing Capacity of Rails and the Stiffness of the Optimized Sleepers," Procedia Technol., 22, 312-318 (2016).

12. A. Benedetto, F. Tosti, L. Bianchini Ciampoli, A. Calvi, M. G. Brancadoro, A. M. Alani, Railway ballast condition assessment using ground-penetrating radar - An experimental, numerical simulation and modelling development, Constr. Build. Mater., 140, 508-520 (2017).

13. Z. Zhang, X. Zhang, H. Qiu, M. Daddow, Dynamic characteristics of track-ballast-silty clay with irregular vibration levels generated by high-speed train based on DEM, Constr. Build. Mater., 125, 564-573 (2016).

14. S. Kaewunruen and A. M. Remennikov, Sensitivity analysis of free vibration characteristics of an in situ railway concrete sleeper to variations of rail pad parameters, J. Sound Vib., 298, no. 1-2, 453-461 (2006).

15. S. Zhang, X. Xiao, Z. Wen, X. Jin, Effect of unsupported sleepers on wheel/rail normal load, Soil Dyn. Earthq. Eng., 28, no. 8, 662-673 (2008).

16. R. Ferrara, G. Leonardi, F. Jourdan, "SIIV - 5th International Congress - Sustainability of Road Infrastructures Numerical Modelling of Train Induced Vibrations, Procedia Soc. Behav. Sci., 53, no. 0, 155-165 (2012).

17. D. Inman, Engineering vibration, 4th ed. Boston: Pearson, 16 - 58, (2014). 
18. W. Zhai, K. Wang, J. Lin, Modelling and experiment of railway ballast vibrations, JSV, 270, no. 4-5, 673-683 (2004).

19. J. Stead and M. Kerr, Spc 232 concrete sleepers, (2012).

20. D. P. Connolly, G. Kouroussis, P. K. Woodward, P. Alves Costa, O. Verlinden, M. C. Forde, Field testing and analysis of high speed rail vibrations, Soil Dyn. Earthq. Eng., 67, 102-118 (2014).

21. S. A. Suhairy, Prediction Of Ground Vibration From Railways, Undergraduate Graduate Thesis, Swedish National Testing and Research Institute (2000).

22. I. Crespo-Chacón, J. García-de-la-Oliva, E. Santiago-Recuerda, On the Use of Geophones in the Low-Frequency Regime to Study Rail Vibrations, Procedia Engineering, 143, 782-794 (2016).

23. S. Rao, Mechanical vibration, 5th ed. Reading, Massachussetts: Addison Wesley, 257 - 374 (2011).

24. Federal Transit Administration, Transit Noise and Vibration Impact Assessment, (2006). 